\title{
Um par de cantoneiras pelo ebanista Jean-Henri Riesener
}

\author{
A pair of demi-lune tables by ébéniste Jean-Henri Riesener
}

Tiago Rodrigues ${ }^{1}$;

${ }^{1}$ E-mail: tiagorodrigues2@campus.ul.pt Investigador ARTIS-IHA/CH-UL
Resumo: Com este artigo pretendemos estudar a relação que existe entre museus, instituições e o mercado de arte português. O nosso objeto de estudo será um par de cantoneiras estampilhadas pelo ebanista Jean-Henri Riesener que apareceram no mercado de arte português, no ano de 2018, na Cabral Moncada Leilões.

Estudaremos o trabalho deste ebanista francês (o favorito da rainha Maria Antonieta), o facto das suas peças terem sido dispersas com a Revolução Francesa, e a sua presença em coleções públicas portuguesas.

Terminaremos a abordar a fortuna histórica das recentes peças que chegaram ao mercado de arte nacional, com o intuito de mostrar que a relação entre museus, instituições, cujas coleções são constituídas por bens artísticos, e o mercado de arte complementam-se.

Palavras-chaves: mobiliário francês; Jean-Henri Riesener; Colecionismo de arte; Cabral Moncada Leilões.

Abstract: With this article we intend to study the relationship between museums, institutions and the Portuguese art market.

Our object of study will be a pair of demi-lune tables stamped by the ébéniste Jean-Henri Riesener that appeared in the Portuguese art market in 2018 at Cabral Moncada Auctions House.

We will study the work of this French ébéniste (the favorite of Queen MarieAntoinette), the fact that his pieces were scattered with the French Revolution, and their presence in Portuguese public collections.

We will conclude by addressing the historical fortune of the recent pieces that have reached the national art market, in order to show that the relationship between museums, institutions, whose collections are made up of artistic assets, and the art market complement each other.

Keywords: French furniture; Jean-Henri Riesener; Art collecting; Cabral Moncada A uctions House. 


\section{1) Jean-Henri Riesener}

O ebanista Jean-Henri Riesener (1734-1806) (Fig. 1) alcançou o sucesso e o reconhecimento profissional após a entrega do bureau du roi ${ }^{1}$ em maio de 1769.

A corte francesa passou a admirar esta peça e muitos nobres realizaram uma série de encomendas inspiradas no mesmo modelo. São disto exemplo duas secretárias de cilindro, uma que se pode contemplar no Museu Calouste Gulbenkian, e outra no Museu Nacional de Arte Antiga, ambas em Lisboa (Verlet e Wittman, 1955: 5 e 6).

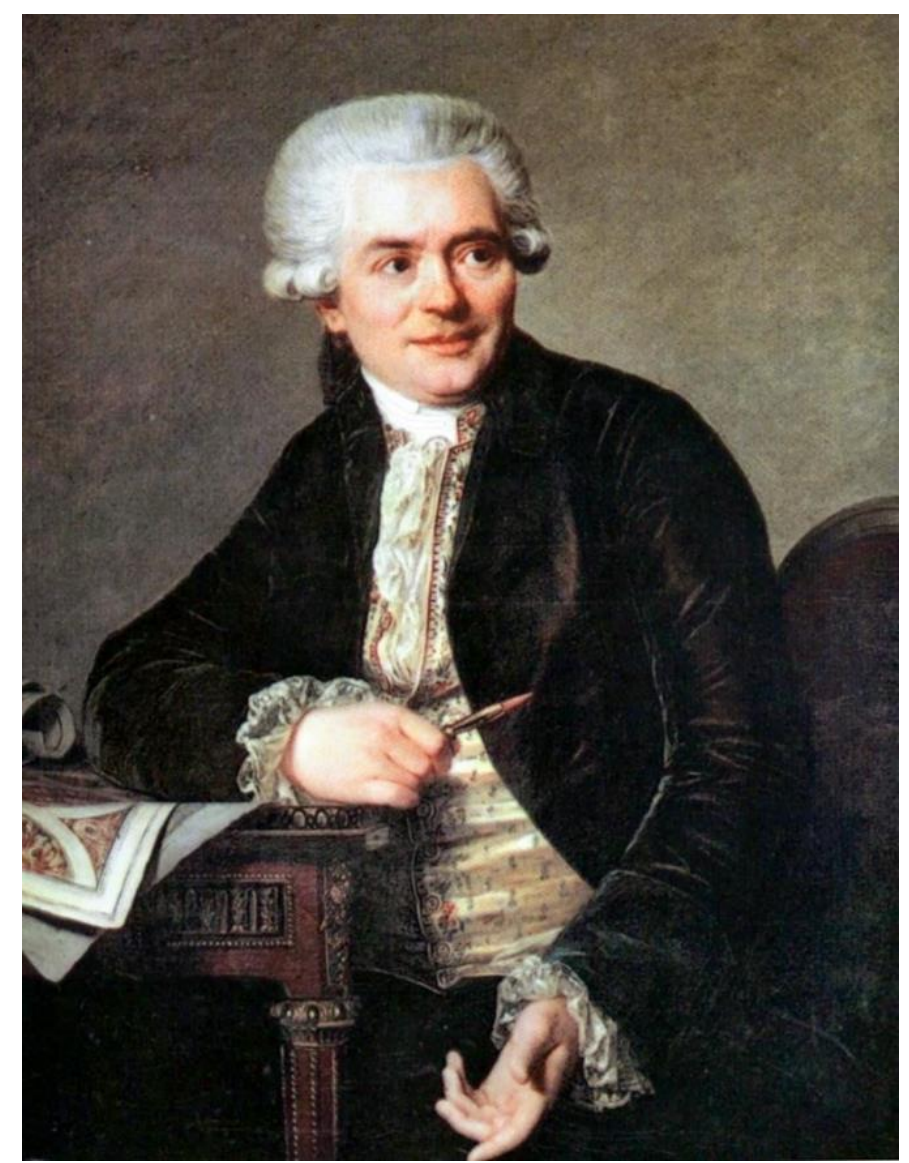

Fig 1: Retrato do ebanista Jean-Henri Riesener (vista geral); Antoine Vestier, 1786, França, séc. XVIII ( $2^{\circ}$ metade), óleo sobre tela. 120 x 101,5 x 7,5 cm; Château de Versailles, Versailles, França, (fot.: http://collections.chateauversailles.fr/\#8ac69dbc-2da2-4cda-98dc$\underline{\text { e825ff43ad84 }[25 / 08 / 2018]) ;}$

\footnotetext{
${ }^{1}$ Concebida e iniciada pelo ebanista Jean-François Oeben, que ocupou os últimos anos da sua vida com a realização de estudos, desenhos e maquetes para a sua conceção, à data da sua morte apenas a estrutura estava concluída. Como seu discípulo Riesener acabou por ser o responsável por a finalizar, dedicando-se à aplicação e afinação de todos os mecanismos e trabalhos de serralharia, bem como à decoração em marchetaria e aos bronzes cinzelados e dourados que a tornam numa peça exuberante.
} 
O seu trabalho caracteriza-se pela presença de marchetados onde estão representadas flores. Serve-nos de exemplo a secretária de cilindro do Museu Calouste Gulbenkian que em toda a sua superfície apresenta uma decoração que consiste em várias composições florais. Tanto nas costas do cilindro como na cintura. À exceção das ilhargas em que é mostrado um medalhão central, preenchido por uma composição de folhas e bagas, em forma de rosácea ladeada por dependências embelezadas com diversos frutos, dos quais despontam exíguas flores ou folhas, sobretudo de parra. Toda esta ornamentação, de um realismo notável, consegue transmitir de forma perfeita as diversas texturas, ora acetinadas ora aveludadas, engelhadas ou ásperas de cada elemento floral (Coutinho, 1999: 215-217).

Outra característica do seu trabalho diz respeito ao jogo de tonalidades e de formas geométricas que realiza com diferentes qualidades de madeiras, o que mostra a sua habilidade como marceneiro. Essa capacidade está bem presente na secretária de cilindro que observamos no acervo do MNAA (Fig. 2).

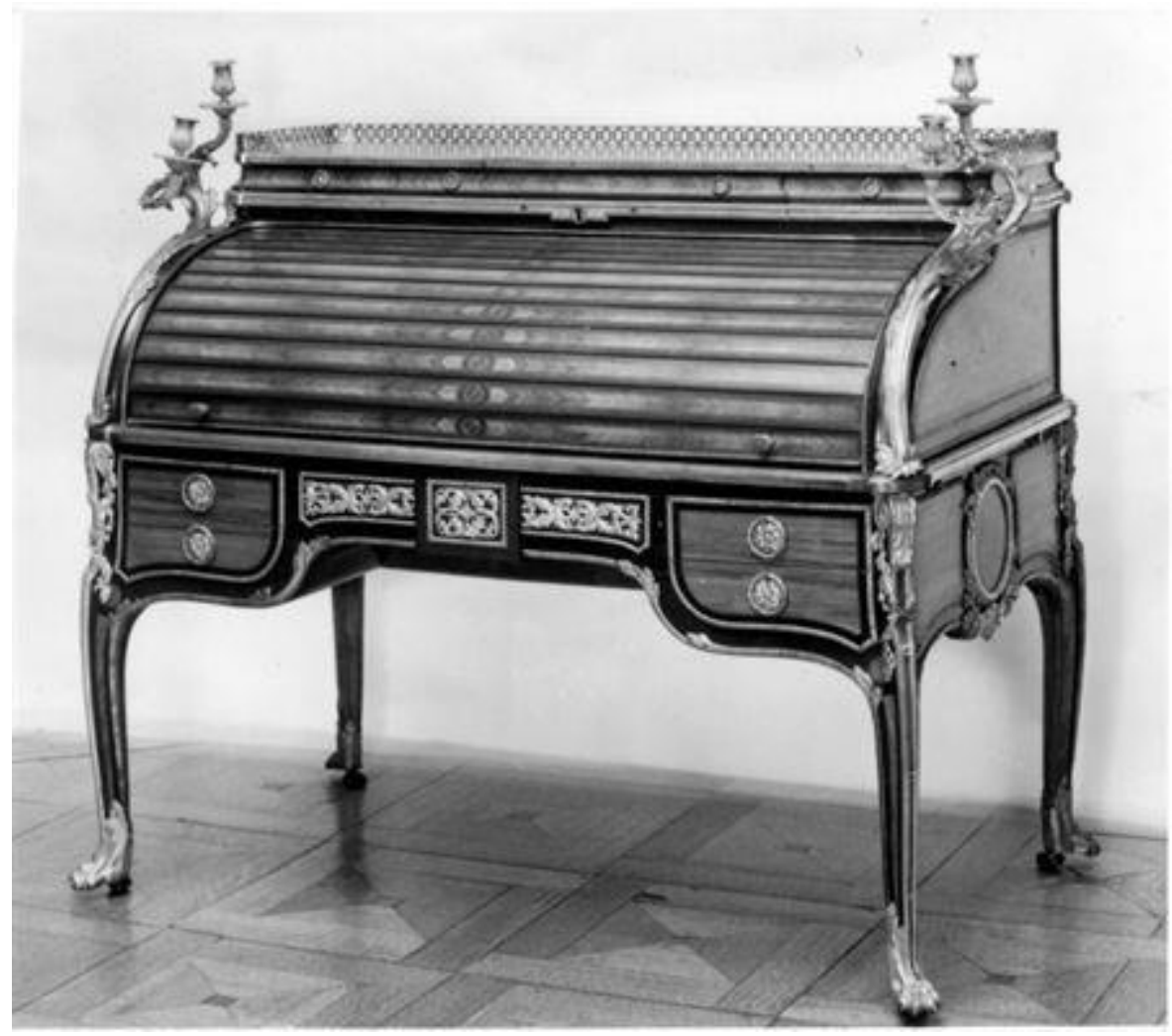

Fig. 2: Secretária de cilindro; Jean-Henri Riesener, c.1780, França, séc. XVIII (2ºtade), Carvalho, pau santo, pau rosa, ébano, "citronier", faia, bronze e marroquim negro. 119 x 145 x $84.5 \mathrm{~cm}$; Museu Nacional de Arte Antiga, Lisboa. (fot.: http://www.matriznet.dgpc.pt/MatrizNet/Objectos/ObjectosConsultar.aspx?IdReg=260529 $[25 / 08 / 2018])$ 
$\mathrm{Na}$ zona do cilindro apresenta a superfície com uma decoração de marchetaria em espinhado. No entanto, no topo e nas costas a decoração mostra-se compartimentada em reservas, sendo a central preenchida com um esquema de losangos que se repete nas ilhargas (onde se observam medalhões circulares com um monograma inscrito). As arestas deste móvel são emolduradas por bronzes cinzelados que, no topo, formam uma balaustrada, interrompida na frente, constituída por uma composição de óvulos vazados. As arestas dianteiras do cilindro são percorridas por uma moldura de ramagem naturalista que arranca de um leque de folhas, até se elevar e entrelaçar no topo, de modo a formar o apoio dos dois candelabros de dois lumes.

Nas ilhargas do corpo inferior, os medalhões são emoldurados por perlados, fitas e folhas de loureiro. Nas arestas do corpo inferior, os bronzes desenvolvem-se a partir de mísulas com festões, desenvolvendo-se em perlados nas arestas dianteiras das pernas, enquanto nas arestas laterais apresenta uma moldura de folhagem que se prolonga pela frente do móvel. Os pés são calçados por bronzes em garra com folhagem, assentando sobre rodízios. As argolas dos puxadores têm a forma de uma coroa de louros, e o espelho é formado por um florão (Coutinho, 1994:50-56).

Como podemos ver, outra característica do labor deste ebanista é a presença de bronzes dourados. Ao contrário de muitos dos seus contemporâneos, os acabamentos das suas peças permitiam disfarçar parafusos e pregos através do uso de detalhes em bronze. Esta ideia é justificada com a pintura realizada por Vestier (Fig.1) que nos mostra o marceneiro junto a uma das suas mesas, sobre a qual estão depositados desenhos para montagens em bronze dourado (Verlet,1967:26).

Sabemos também que, na década de 1780, colaborou com Pierre Gouthière (1732-1816) e com François Rémond (1747-1812) em encomendas reais como a secretária e a cómoda que hoje estão no Metropolitan Museum of Art e o contador com suporte para jóias da condessa de Provença, que hoje faz parte da Royal Collection.

No início da sua carreira, Riesener ainda apresentava um trabalho de natureza rococó. No entanto, num período cronológico compreendido entre 1760-1765 e 1775, o mesmo em que as secretárias de cilindro foram realizadas, as curvas predominantes começaram a dar lugar a linhas mais retas. Por exemplo, as pernas que eram predominantemente galbadas e calçadas por garras de leões, passam a terminar em linha reta, quase aprumada, e os pés transformamse em pequenas balaustradas.

Simultaneamente, a nível dos bronzes, observa-se um abandono dos temas florais e a 
representação de grinaldas de louro, rosáceas, cabeças de carneiros ou de leões, trazem uma nova gramática decorativa, inspirada na Antiguidade.

Por sua vez, o contador com suporte para jóias da condessa de Provença, que faz parte da Royal Collection reflete a imponência do trabalho deste ebanista, numa altura (c. 1787) em que já não recebia o apoio do rei, mas continuava a produzir para uma clientela abastada. Trata-se de uma peça em mogno, ricamente decorado com bronzes dourados, que apresenta uma superestrutura composta por um grupo de putti que seguram uma coroa que encima o brasão da condessa, flanqueado por vasos de frutas. O friso com três gavetas apresenta, tal como a peça anterior, bronzes em alto relevo onde se observa uma alegoria à astrologia com putti. As duas portas encontram-se ricamente decoradas com bronzes alegóricos à música que são flanqueadas por cariátides. Por cima das duas portas do armário surgem troféus, ladeado por duas figuras femininas e no seu interior são visíveis dezoito gavetas e três prateleiras (Verlet e Bullock, 1963). Os folheados de mogno simples são característicos da produção de Riesener do final da década de 1780. O mogno permite realizar uma cobertura deliberada sobre a qual são colocadas as montagens em bronze, que acabam por ser tratadas como esculturas, deixando de haver aquele trabalho de marchetaria como observamos nas produções anteriores. Passa a haver uma combinação entre o trabalho do marcheteiro e o do bronzista, neste caso, atribuída a François Rémond (1747-1812) (Verlet e Bullock, 1963). E é na simplicidade do mogno que encontramos as semelhanças com as duas cantoneiras que foram leiloadas em Lisboa na Cabral Moncada Leilões no mês de maio de 2018.

\section{2) Dispersão da obra de Riesener}

Logo no início do século XIX, os colecionadores do Reino Unido adquiriram um número significativo de móveis que faziam parte do recheio dos palácios reais franceses. Retirados dos salões para onde foram concebidos, tornaram-se a base das grandes coleções de mobiliário francês que ainda hoje permanecem no Reino Unido. Destaca-se, como exemplo, a coleção Rotschild, a coleção de George Watson Taylor e a Royal Collection Trust.

Por sua vez, entre o final da era industrial e até à depressão agrícola da década de 1920, um grande número destas obras, predominantemente de coleções do Reino Unido, foram leiloadas por casas como a Christie's e a Sotheby's, e acabaram por ser adquiridas por alguns milionários norte-americanos. Atualmente repousam em museus dos EUA, como serve de exemplo a cómoda em carvalho folheado com ébano e laca japonesa, com montagens de bronze dourado e tampo de mármore que faz parte do acervo do Metropolitan Museum of 
Art em Nova Iorque (fig. 3).

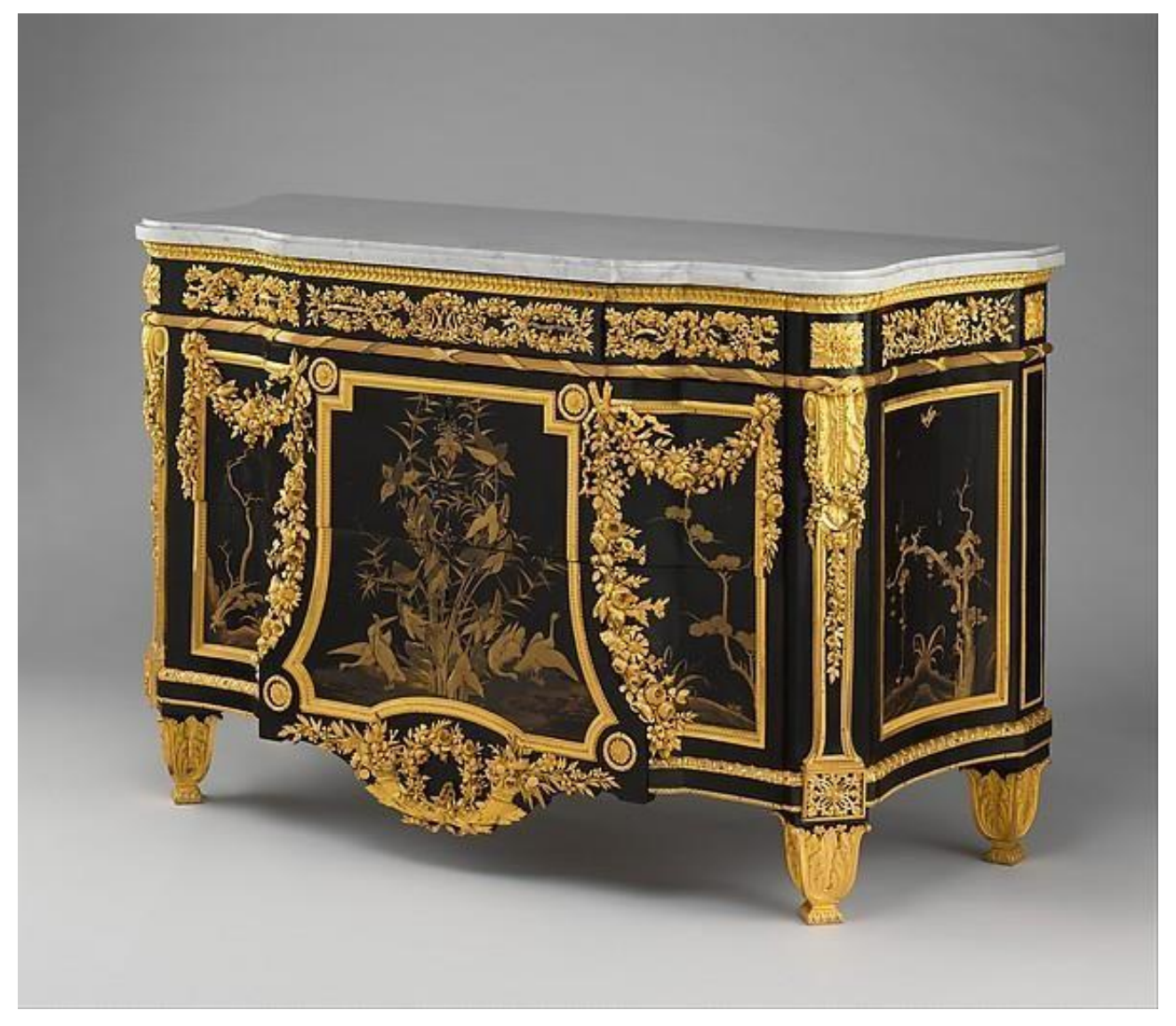

Fig. 3: Cómoda; Jean-Henri Riesener, 1783, França, séc. XVIII (2 metade), Carvalho folheada com ébano e laca japonesa do século XVII; interiores folheados com tulipa amaranto e azevinho, Montagens de bronze dourado; tampo de mármore; veludo (não original). 93.3 x 143.5 x $59.7 \mathrm{~cm}$; Metropolitan Museum of Art, Nova Iorque. (fot.: https://www.metmuseum.org/art/collection/search/194623?searchField=All\&amp;sortBy=relevance\& amp;ft=riesener\&amp;offset=0\&amp;rpp=20\&amp;pos=4 [25/08/2018]).

Este é um bom exemplo da dinâmica do património artístico, e da circulação das obras deste ebanista. No ano de 1787, juntamente com uma secrétaire à abbatant ${ }^{2}$, esta peça foi enviada de Versailles para Saint-Cloud para redecorar os aposentos privados da rainha. No entanto, ambas as peças deixaram as coleções reais quando foram dadas como forma de pagamento ao fornecedor de suprimentos do exército, Abraham Alcan. Durante os inícios do século

\footnotetext{
${ }^{2}$ A secrétaire à abbatant surgiu em França nos meados do século XVIII. Apresenta a parte superior baixa de maneira a criar uma superfície para escrever, forrada a pele (Miller, 2000:83).
} 
XIX, fizeram parte da coleção de George Watson Taylor que as manteve na sua casa de campo em Wiltshire, Erlestoke Park. Nos anos de 1820 foram vendidas, juntamente com outras peças estampilhadas por Riesener (destacam-se as peças adquiridas pelo rei George IV e que hoje fazem parte da Royal Collection). Depois disso, pertenceram aos duques de Hamilton, que as venderam no leilão realizado no ano de 1882, onde foram adquiridas por William Kissam Vanderbilt (1853-1933) para a sua mansão na quinta avenida em Nova Iorque. Depois da sua morte foram legadas ao museu que as exibe na Gallery 899.

No entanto, ainda hoje, as coleções do Reino Unido são especialmente ricas em mobiliário francês, particularmente de proveniência real, o que faz daquele país o maior repositório de obras de Jean-Henri Riesener fora de França. Destacam-se, para alem das já referidas Royal Collection e Waddesdon Manor, a coleção do Victoria and Albert Museum e a Wallace Collection.

\section{2) Riesener nas coleções portuguesas}

Por sua vez, em Portugal não encontramos um considerável número de peças estampilhadas por Riesener e as poucas que existem foram aquisições realizadas por Calouste Gulbenkian que as doou a Portugal.

Uma é a secretária de cilindro do Museu Calouste Gulbenkian, que pertenceu aos aposentos da condensa de Provença no Château de Versailles e que foi transferida para o Château de Marly e, em seguida, para o Palais des Tuileries, onde foi colocada ao serviço da irmã do rei Luís XVI, Madame Isabel (1764-1794). Esta peça foi adquirida ao Barão de Rothschild, a 10 de setembro de 1931, por intermédio da Mme Petrocochino, para Calouste Gulbenkian. No mesmo museu temos uma mesa secretária encomendada, com outros móveis, para os aposentos da Rainha Maria Antonieta no Château de Marly. Esta peça foi adquirida pelo colecionador ao governo soviético no ano de 1929 (Coutinho, 1994).

Um terceiro exemplo é a secretária de cilindro do MNAA, que terá sido encomendada por um descendente de Samuel Bernard, Conde de Coubert, e que se manteve nas mãos de particulares, em França, até à sua aquisição por Calouste Gulbenkian em 1928 na Galerie G. Petit. Nessa altura pertencia a Mme La Verteville e, no ano de 1952, foi doada ao MNAA (Coutinho, 1994).

Atribuída a Riesener há ainda uma cómoda, ricamente ornamentada com motivos de bronze cinzelados e dourados que apresenta um trabalho mosaicado ao gosto do mestre.

Por fim, temos o par de cantoneiras que surgiu em maio de 2018 no leilão da Cabral 
Moncada Leilões. Trata-se de uma peça adquirida no ano de 1953 por um colecionador português e, a par disso, pode ser um dos melhores exemplos do mobiliário deste ebanista em coleções privadas nacionais.

\section{3) O par de cantoneiras leiloadas na Cabral Moncada Leilões}

\section{1) Fortuna histórica}

O par de cantoneiras (Fig.4), que serve de mote a este estudo, pertenceu à bailarina Pauline Duvernay (1812-1894).

Aluna de Hippolyte Barrez na Ópera de Paris, onde também trabalhou com Auguste Vestris, Jean-François Coulon e Filippo Taglioni, a sua habilidade para a dança, bem como a sua beleza, ajudaram-na a cativar o público de Paris e de Londres em óperas de Jean-Baptiste Blache e de Jean-Pierre Aumer. No entanto, no ano de 1837, no auge da sua carreira, deixou os palcos, dedicou-se a causas de caridade, e casou-se com o banqueiro e membro do Parlamento inglês, Stephens Lyne-Stephens que no ano de 1856 adquire Lynford Hall (Glass, 2003).

No ano de 1860 Pauline ficou viúva e sem filhos, e viu a fortuna do seu marido ser entregue a um dos seus filhos ilegítimos. No entanto, o resto da sua vida esteve sempre envolvida com a arte e com o património ${ }^{3}$. O seu gosto pela arte é-nos esclarecido no ano a seguir à sua morte, quando nos dias 9- 11 de maio de 1895, é realizado um leilão em Londres, pela Christie's, da sua coleção de pintura, porcelanas, objetos de arte e mobiliário. Trata-se de mais de 1000 lotes, sendo que o número 270 diz respeito às duas cantoneiras que agora se estuda (Christie's, 1895).

Posteriormente, pertenceram a Mrs. Louis Raphael e, a 18 de maio de 1927, foram vendidas, também pela Christie's, em Londres. Finalmente, foram adquiridas no ano de 1953, em Londres, por um colecionador português.

\footnotetext{
${ }^{3}$ Entre 1885 e 1890 financiou a construção da Igreja Católica de Nossa Senhora e dos Mártires ingleses na cidade de Cambridge, uma igreja em estilo gótico revivalista, traçada pelos arquitectos Dunn \& Hansom. No ano de 1888 foi pintada por Carolus-Duran (fig. 10), o mesmo pintor francês que em 1880 já havia pintado a rainha D. Maria Pia de Portugal.
} 


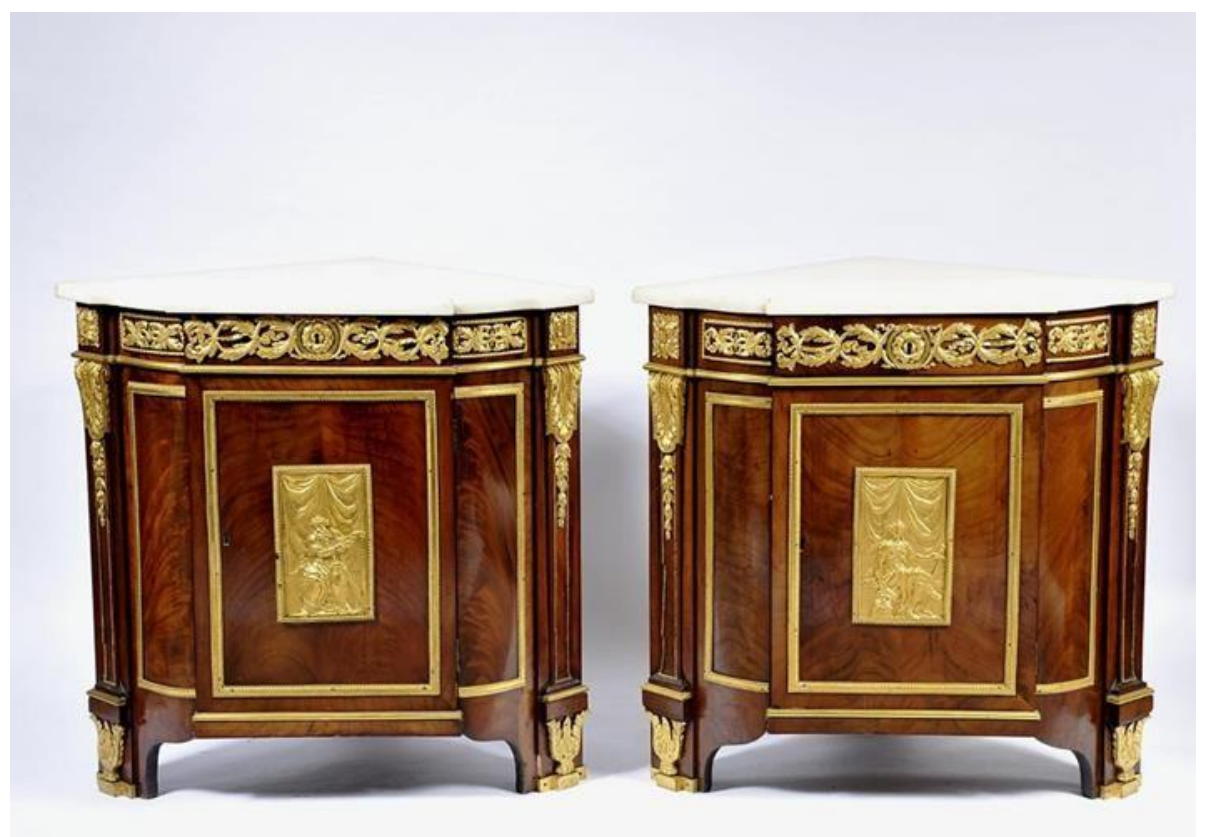

Fig. 4: Par de cantoneiras; Jean-Henri Riesener, c.1780, França, séc. XVIII ( $2^{\circ}$ metade), Carvalho revestido a faixeado de mogno e raiz de mogno, bronzes dourados. 94,5 x 97 x 65,5 cm; Cabral Moncada Leilões, Lisboa. (fot.: https://www.cml.pt/leiloes/2018/194-leilao/2sessao/592/par-de-cantoneiras [25/08/2018]).

\section{2) Análise descritiva do par de cantoneiras}

Estas cantoneiras (fig.4), realizadas em carvalho revestido e faixeado de mogno e raiz de mogno, tal como observamos nos móveis de Riesener da década de 1780, apresentam a frente das gavetas em mogno e encontram-se adornadas por aplicações de bronze relevado, cinzelado e perlado que imitam folhas de acanto. Os tampos são em mármore francês. No centro de cada porta observamos um medalhão retangular datado do século XIX. Em bronze dourado relevado, estes apresentam o "Rei Salomão" num lado e, no outro, "Salomé”. Uma das cantoneiras é estampilhada RIESENER, o que as torna como raros trabalhos deste ebanista no mercado de arte português.

Encontramos semelhanças deste lote com um par de cantoneiras que nos inícios do século XXI, no leilão da Christie's Ancienne collection du Baron Hottinguer, que se realizou nos dias 2 e 3 de dezembro de 2003 em Paris. Tais peças tinham um valor estimado entre os 100.000 EUR e os 150.000 EUR e foram arrematadas pelo preço de martelo de 558.250 
EUR. $^{4}$

\section{4) Considerações finais}

Com este estudo conseguimos perceber como a obra de Jean-Henri Riesener, que é paradigma da introdução do classicismo na arte decorativa francesa, é pouco valorizada no contexto do mercado de arte português, onde prevalece o gosto pelo mobiliário nacional do reinado D. João V, D. José e D. Maria I.

Estamos perante o trabalho de um dos mais importantes ebanistas da $2^{\circ}$ metade do século XVIII francês - é ele que realiza a transição entre o rocaille do seu mestre Oeben e as linhas austeras que vigoram no estilo Império dos inícios de 1800.

Embora a sua obra tenha sido apreciada pelos grandes colecionadores do séc. XIX e inícios do XX como os Rothschild, os Vanderbilt e Calouste Gulbenkian e por isso alvo do colecionismo, e depois copiada pelos ebanistas da segunda metade do século XIX, grande parte das obras de Riesener estão hoje em coleções museológicas, e apenas uma pequena minoria encontra-se na mão de colecionadores privados, fazendo com que seja a qualidade e a raridade a valorizarem a sua obra no panorama do mercado de arte internacional.

No entanto, o mesmo não acontece no panorama nacional. Por encontrar-se representado em instituições de prestígio como o Museu Calouste Gulbenkian e o Museu Nacional de Arte Antiga, que funcionam como agentes no circuito comercial, interferindo e valorizando o valor de mercado, incentivando indiretamente a procura de mobiliário com as mesmas características do que as apresentadas nas suas salas, a obras de Riesener poderia ser alvo de despique quando foram apresentadas em praça pela Cabral Moncada Leilões. No entanto, não foi o que aconteceu e o lote foi arrematado pelo valor base de 50.000 EUR. Com isto podemos considerar que a relação entre museus, instituições, cujas coleções são constituídas por bens artísticos, e o mercado de arte nem sempre se complementam.

${ }^{4}$ https://www.christies.com/lotfinder/Lot/paire-dencoignures-depoque-louis-xvi-estampille-de-4211509-details.aspx [21/08/2018] 


\section{Referências bibliográficas}

AA. VV - Museus, Palácios e Mercados de Arte, Museums, Palaces and Art Market. Scribe: Lisboa, 2014.

AA. VV. - A Arte do Retrato. Quotidiano e Circunstância, catálogo de exposição. Lisboa: Museu Calouste Gulbenkian, 1999

AA. VV. - Chefs d'oeuvres du musée gulbenkian de lisbone: meubles et objects royaux du xviii siècle français. Lisboa: Fundação Calouste Gulbenkian, 2000

AA. VV - Le mobilier du Musée du Louvre. Dijon: Editions Faton, 1993

BOLL, Dirk - Art for sale, a candid view of the art market, Hatje Cantz [s.d.].

BURCKHARDT, Monica - Mobilier Louis XVI. Paris: Charles Massin, [s.d.]. - Mobilier régence Louis XV. Paris : Charles Massin, [s.d.].

CABRAL MONCADA LEILÕES - Antiguidades $e$ Obras de Arte moderna $e$ contemporânea, 28 e 29 de Maio de 2018.

COUTINHO, Maria, Isabel - O mobiliário francês do século XVIII. Lisboa: Museu Calouste Gulbenkian, 1999.

- "Mobiliário", in Calouste Sarkis Gulbenkian. Uma doação ao Museu Nacional de Arte Antiga. No $25^{\circ}$ aniversário do Museu Calouste Gulbenkian. Lisboa: Fundação Calouste Gulbenkian, 1994.

FERNANDES, Alexandra, AFONSO, Luís Urbano - Os leiloes e o mercado da arte em Portugal, Estrutura, História e tendências. Scribe: Lisboa, 2012.

FORRAY-CARLIER, Anne - Le mobilier du château de Chantilly, Edition Faton, 2010.

LINLEY, Charles, CATOR, Charles, CHISLETT, Helen - The Enduring Beauty of

Spectacular Furniture. London : Thames \& Hudson, 2009.

PAYNE, Christopher - $19^{\text {th }}$ Century European Furniture, Antique Collectors 'Club, 1985.

ROBERTS, Jennifer - Glass: The strange history of the Lyne Stephens Fortune. USA:

Templeton Press, 2003.

SALVETRE, François de - Les ébenistes du XVIII siècle : Leurs oeuvres et leurs marques.

New ed. Paris and Brussels, 1927.

VERLET, Pierre - Le mobilier royal français du XVIIIe siècle. IV-Meubles de la Couronne conservés en Europe et aux États-Unis. Paris : Editions Picard, 1990.

- Les ébénistes du XVIII siècle français. Paris : Hachette, 1963.

- Les meubles français du XVIII siècle, $2^{\circ}$ edição. Paris : Presses Universitaire de

France, 1982. 
, BULLOCK, Michael - French royal furniture: an historical survey followed by a study of forty pieces preserved in Great Britain and the United States. London: Barrin and Rockliff, 1963.

, WITTMAN, René - Le mobilier royal français: meubles de la couronne conserves en France Avec une etude sur le gardemeuble de la Couronne. Paris: Edition Plon, 1955. 